Please do not remove this page

RMIT

UNIVERSITY

\title{
Is all salinity the same? I. The effect of ionic compositions on the salinity tolerance of five species of freshwater invertebrates
}

Zalizniak, Liliana; Kefford, Benjamin; Nugegoda, Dayanthi

https://researchrepository.rmit.edu.au/esploro/outputs/9921859564001341/filesAndLinks?institution=61RMIT_INST\&index=null

Zalizniak, L., Kefford, B., \& Nugegoda, D. (2006). Is all salinity the same? I. The effect of ionic compositions on the salinity tolerance of five species of freshwater invertebrates. Marine and Freshwater Research, 57, 75-82. https://doi.org/10.1071/mf05103

Published Version: https://doi.org/10.1071/mf05103

Repository homepage: https://researchrepository.rmit.edu.au

(c) CSIRO 2006

Downloaded On 2023/04/26 20:59:45 +1000

Please do not remove this page 
Is all salinity the same? I. The effect of ionic compositions on the salinity tolerance of five species of freshwater invertebrates.

3 Liliana Zalizniak, Ben J. Kefford ${ }^{\mathrm{A}}$, and Dayanthi Nugegoda

5

6 Biotechnology and Environmental Biology, School of Applied Sciences, RMIT University, PO Box 71, Bundoora 3083, Vic, Australia

Citation:

Zalizniak, L, Kefford, B and Nugegoda, D 2006, 'Is all salinity the same? I. The effect of ionic compositions on the salinity tolerance of five species of freshwater invertebrates', Marine And Freshwater Research, vol. 57, pp. 75-82. 


\section{Abstract}

3 Salts of marine origin, predominantly consisting of $\mathrm{Na}^{+}$and $\mathrm{Cl}^{-}$ions are dominant in

4 most Australian inland saline waters. The proportions of other ions, $\mathrm{Ca}^{2+}, \mathrm{Mg}^{2+}, \mathrm{SO}_{4}{ }^{2-}$

$5 \mathrm{HCO}_{3}{ }^{-}$and $\mathrm{CO}_{3}{ }^{2-}$, in the water may influence salinity tolerance of freshwater

6 organisms and thus the effect of increasing salinity may vary with difference in ionic

7 proportions. We exposed freshwater invertebrates to different concentrations of four

8 ionic compositions and compared them to the commercial sea salt, Ocean Nature.

9 They were: synthetic Ocean Nature (ONS) and three saline water types (ONS but

10 without [1]: $\mathrm{SO}_{4}{ }^{2-}, \mathrm{HCO}_{3}{ }^{-}$and $\mathrm{CO}_{3}{ }^{2-},[2]: \mathrm{Ca}^{2+}, \mathrm{HCO}_{3}{ }^{-}$and $\mathrm{CO}_{3}{ }^{2-},[3]: \mathrm{Ca}^{2+}, \mathrm{Mg}^{2+}$ )

11 which are considered to be the predominant saline water types in southeastern

12 Australia and the Western Australian wheatbelt. The 96-h LC $_{50}$ values for the five

13 media were determined for six invertebrate species and sub-lethal responses were

14 observed for two species. There were no differences between responses of

15 invertebrates to various ionic compositions in acute toxicity tests. However in

16 prolonged sub-lethal tests animals reacted differently in the various ionic

17 compositions. The greatest effect was observed in water types lacking $\mathrm{Ca}$ for which

18 plausible physiological mechanisms exist. Variation in ionic proportions should be

19 taken into account when considering sub-lethal effects of salinity on freshwater

20 invertebrates.

21

22 Keywords: salinity, ionic compositions, freshwater invertebrates, toxicity 


\section{Introduction}

3 The salinization of freshwaters is a major environmental concern in all continents

4 with large arid and semiarid regions, including Australia (Williams 1987). Recently

5 attention has been given to the lethal (Berezina 2003, Kefford et al. 2003) and sub-

6 lethal tolerance (Kefford and Nugegoda 2005a) of freshwater invertebrates to

7 increased salinity, while other studies have experimentally considered effects of

8 salinity on freshwater invertebrate communities (Neilsen et al. 2003, Marshall and

9 Bailey 2004). All of these studies used artificial sea salts, the ionic proportion of

10 which approximates seawater, because it is the most common composition of saline

11 water bodies of southeastern Australia (Bayly and Williams 1973), which are sodium

12 chloride $(\mathrm{NaCl})$ dominated. However recently it has been acknowledged that there is

13 some variation in the ionic proportion of $\mathrm{NaCl}$-dominated inland saline waters of

14 southeastern Australia (Radke et al. 2002, 2003). The three major saline water types

15 existing in southeastern Australia (Radke et al. 2002), and the wheatbelt region of

16 Western Australia (Pinder et al. 2005), were proposed by Drever (1982) and occur

17 due to precipitation out of solution of specific minerals during evapoconcentration of

18 saline waters and result in reductions in the relative concentrations of specific ions. If

19 variations in ionic proportions in $\mathrm{NaCl}$-dominated inland saline waters result in

20 differing biological effects, then studies investigating the effects of saline water with a

21 particular ionic proportions (such as seawater) may not accurately describe the effects

22 of changes in salinity with differing ionic proportions. Consequently, we investigated

23 whether these three common ionic proportions and artificial seawater altered lethal

24 and sub-lethal effects of salinity on freshwater invertebrates. For the common ionic

25 proportions we used the most extreme cases where specific ions are eliminated from a 
1 saline water source, and therefore refer to the ionic compositions (presence/absence of

2 specific ions), because if the absence of specific ions do not affect salinity tolerance

3 then it is very unlikely that a reduction in the proportions of these ions would affect

4 salinity tolerance.

\section{Materials and methods}

\section{Test animals}

9 Six species of freshwater invertebrates were used for acute $96-\mathrm{h} \mathrm{LC}_{50}$ toxicity testing 10 ( $\mathrm{LC}_{50}$ is the concentration of a toxicant lethal to $50 \%$ of a population). The protozoan

11 Paramecium caudatum Ehrenberg and hydrozoan Hydra oligactis Pallas were 12 purchased from Southern Biological, Nunawading, Victoria, Australia. Other species, 13 collected from central Victoria, in the southern end of the Murray-Darling Basin were: 14 gastropod Physa acuta Draparnaud (Campaspe River, at the Kyneton-Heathcote Rd. $15\left(37^{\circ} 23\right.$ 'S $\left.\left.144^{\circ} 31^{\prime} \mathrm{E}\right)\right)$, caddis fly Notalina fulva Kimmins, water bug Micronecta 16 robusta Hale and mayfly Centroptilum sp. (King Parrot Creek, a tributary of the 17 Goulburn River, at Flowerdale $\left(37^{\circ} 23^{\prime} \mathrm{S}, 145^{\circ} 16^{\prime} \mathrm{E}\right)$. These specific species were 18 chosen because they represent a wide range of different taxonomic groups found in 19 freshwaters and were obtainable in sufficient numbers to experimentally expose to 20 varying salinity and ionic composition treatments. Previous experiments where 21 macroinvertebrate species have been collected from different sites or from the same 22 site on different dates have shown no detectable difference in acute lethal salinity 23 tolerance (Kefford et al. 2003, 2005, unpublished data). This is despite large 24 differences in the acute lethal salinity tolerance between species. We thus assume that 25 any difference in salinity tolerance or response to the different ionic compositions of 
1 species obtained from different sources represent differences between the species tested rather than differing responses of animals collected from different sites.

Water quality data from collection sites are given in an auxiliary publication, Table 1.

Three species, $P$. acuta, $P$. caudatum and $H$. oligactis were used in chronic toxicity tests. The results for P. acuta will be presented elsewhere (Zalizniak et al. in prep). For hydra and paramecia the culture growth in different types of treatments was determined as the measure of sub-lethal toxicity and $\mathrm{EC}_{50}$ values calculated $\left(\mathrm{EC}_{50}\right.$ being the concentration of a toxicant that produced the effect in $50 \%$ of population). For H. oligactis another sub-lethal end point, tentacle retraction, was used.

1

\section{Preparation of solutions}

Five different solutions were tested. Concentrated stock solution of around $40 \mathrm{mS} / \mathrm{cm}$ of Ocean Nature artificial sea salt (ON) (Aquasonic, Wauchope, NSW) was prepared in Milli-Q water and used in preparation of dilutions. Based on both the manufacturers claimed elemental composition and elemental analysis (ICP-MS) of Ocean Nature, 'Ocean Nature Synthesized' (ONS) was prepared from analytical grade reagents. Major ions and trace elements were considered (22 total), and their quantities calculated (see auxiliary publication, Table 2). ON was used as a standard to compare with previous investigations using this salt (Kefford et al. 2003, 2004a,b, 2005a,b), and ONS was used as control for possible effects of synthesized various ionic compositions. Based on ONS preparation three different ionic compositions were derived to reproduce the three major saline water types described in Radke et al. (2002): S1 had the same ionic composition as ONS except there was no sulphates $\left(\mathrm{SO}_{4}{ }^{2-}\right)$ and no carbonates $\left(\mathrm{HCO}_{3}{ }^{-}\right.$and $\mathrm{CO}_{3}{ }^{2-}$, referred to as alkalinity (Alk)); $\mathrm{S} 2$ was 
1 without calcium $\left(\mathrm{Ca}^{2+}\right)$ and $\mathrm{Alk}$, and $\mathrm{S} 3 \mathrm{had} \mathrm{Ca}^{2+}$ and magnesium $\left(\mathrm{Mg}^{2+}\right)$ excluded

2 (Fig. 1; also see auxiliary publication Table 2). Natural S1, S2 and S3 waters have

3 some levels of the elements (see Radke 2002), which we excluded. We excluded them

4 in the stock solutions to represent a worst-case scenario. The control and dilution

5 water had enough of these excluded ions to allow high $(>85 \%)$ survival. Where

6 possible we tried to use carbon filtered Melbourne tap water (WLW) as our dilution

7 water and control. However, lab cultures required specific media for their

8 maintenance. For paramecia we used Lozina-Lozinsky medium (Lozina-Lozinsky

9 1931), and for hydras - M4 medium (Elendt and Bias 1990). Though M4 medium was

10 designed for daphnids, prolonged culturing of hydra (over several months) using this

11 medium was successful. These media served as culture media, dilution water and 12 control in corresponding experiments. The analysis of major ions for some of these 13 media is presented in auxiliary publication, Table 3.

15 Animal cultures

16 Brown hydra $H$. oligactis was fed daily with brine shrimps or juvenile Daphnia carinata (whatever available, since previous observations showed that the cultures survive equally well with either) ad lib. Medium was replaced three times a week.

For paramecia P. caudatum culturing technique was per Sazonova et al. 20 (1997). Lozina-Lozinsky medium was boiled with $0.4 \mathrm{~g} \mathrm{~L}^{-1}$ of dry yeasts and cooled, 21 and then inoculate of culture was introduced. After two days of acclimatising, animals 22 were used for the experiment. Medium was replaced weekly or as necessary. Animals collected from the field were transported from the site to the 24 laboratory and transferred to the testing solutions as quickly as possible (as per 25 Kefford et al. 2003, 2004a, 2005b). 


\section{Acute toxicity testing experimental protocols}

3 There was no water replacement or feeding.

5 Hydras

6 The protocol published by Pollino and Holdway (1999) was used and is only briefly

7 described. Non-budding hydras were used. To achieve this hydra were not fed for 1-2

8 days. Five concentrations of each salt type were used: 4, 6, 8, 10 and $12 \mathrm{mS} \mathrm{cm}^{-1}$

9 replicated 4 times in Petri dishes $(\varnothing 54 \mathrm{~mm})$, with 5 animals per replicate and $15 \mathrm{~mL}$

10 of test solution. Observations were made daily for 96 hours; deaths and tentacle

11 retraction of hydras were recorded. For the tentacle retraction only two rankings were

12 used: 'unaffected' being normal, and 'affected', which is any degree of shortening or

13 disintegration (Pollino and Holdway 1999). It is not certain in the tulip stage if

14 animals are truly dead; consequently at the end of experiment tulip stage animals were

15 transferred to control solution for 48 hours. If animals recovered from the tulip stage, 16 they were counted as alive.

\section{Paramecia}

19 Five concentrations of each salt type were used: $2,4,6,8$, and $10 \mathrm{mS} \mathrm{cm}^{-1}$ each with

2010 animals per concentration held individually in 2-mL wells. Paramecia were fed

21 with the suspension of yeasts $\left(10 \mathrm{~g} \mathrm{~L}^{-1}\right)$ in Lozina-Lozinsky medium every second day

22 (0.02 mL per well). Mortality and numbers present was recorded and $\mathrm{LC}_{50}$ was

23 determined after 24, 48 and 96 hours of exposure. 
1 The rapid toxicity testing method was used (Kefford et al. 2003, 2005b, in press).

2 There were 10 animals of each species per treatment of $3 \mathrm{~L}$ of water. Exposure

3 concentrations were: Centroptilum sp.: WLW $\left(\mathrm{EC} \approx 0.13 \pm 0.01 \mathrm{mS} \mathrm{cm}^{-1}\right), 5,10,15$ and

$420 \mathrm{mS} \mathrm{cm}^{-1}$, and other species: WLW, 10, 15, 20, 25 and $30 \mathrm{mS} \mathrm{cm}{ }^{-1}$. Observations

5 were made daily for 96 hours.

6

$7 \quad$ Sub-lethal toxicity testing experimental protocols

8 Hydra

9 Experimental procedure was as per acute test (Pollino and Holdway 1999) and is only

10 briefly described. However, budding hydras were used. To achieve this hydra were

11 fed in excess for 4-6 days. Three concentrations of each salt type were used: 1, 2 and

$124 \mathrm{mS} \mathrm{cm}^{-1}$. After counting animals and observing tentacle retraction, animals were fed

13 in excess with brine shrimps $(0.2 \mathrm{~mL}$ per dish). After 1 hour all solutions were

14 changed. All parameters for each day were calculated as the geometrical mean 15 between new and old medium.

16 The mean relative growth rate of hydra for each treatment concentration was 17 calculated as follows (Pollino and Holdway 1999):

$$
K=\left(\ln N_{t}-\ln N_{t-1}\right) / \Delta t
$$

19 Where $N_{t}$ is the number of animals at time $t$, $\Delta t$ time between two observations.

Paramecia

24 The experimental protocol is as per acute toxicity testing with paramecia. The culture 25 growth rate (for individual animals) was calculated using a standard formula: 
2 where $N$ is number of animals in the well at time $T$ and $T$ is time from the start of the experiment (days).

\section{Statistics}

6 For each species and treatment type, Probit regression models (see Agresti 1990) were

7 fitted with the x-variable being EC and the y-variable the response variable (survival, 8 population growth or tentacle contraction). From these regressions $\mathrm{LC}_{50}$ and $\mathrm{EC}_{50}$

9 values and their $95 \%$ confidence intervals were calculated for each treatment type. 10 Post hoc comparison of $\mathrm{EC}_{50}$ values was performed using a paired t-test assuming 11 unequal variances.

\section{Results}

\section{Acute tests}

16 For all species examined there were no statistically significant differences in their 96-

$17 \mathrm{~h} \mathrm{LC}_{50}$ values for the different types of treatments (Table 1). The results for 18 Centroptilum sp. (Table 1) are, however, somewhat inconclusive. For treatments other 19 than ON over 96 hours of exposure, they had partial but $<50 \%$ mortality at the 20 lowest salinity treatment, $5 \mathrm{mS} \mathrm{cm}^{-1}$, consequently their $96-\mathrm{h}_{50}$ value is below 5

$21 \mathrm{mS} \mathrm{cm}{ }^{-1}$ for all types of treatments except ON. Since concentrations below $5 \mathrm{mS} \mathrm{cm}{ }^{-1}$ 22 were not tested in this experiment, the error in $\mathrm{LC}_{50}$ calculation is higher than for the 23 other species and thus there is a greater probability of a type 2 error. Across the three 24 species, however, there would appear to be no detectable effect of the different saline 25 water types on acute survival of freshwater invertebrates tested. 


\section{Sub-lethal tests}

2 Though there are differences in tentacle retraction of hydra at 24 hours, they were

3 eliminated at 72 hours (Fig. 2). The $\mathrm{EC}_{50}$ for $\mathrm{S} 3$ salt type initially increased then later

4 decreased. Thus the hydras appear to adapt to their environment when the initial

5 shock is reduced, and they can return to their 'normal' condition. Interestingly 24- and

6 48-h $\mathrm{EC}_{50}$ for $\mathrm{S} 1$ seemed higher (though not statistically significant) than all the

7 others. It may be that sulphates are more toxic to hydra than chlorides and eliminating

8 them results in a marginally reduced overall toxicity.

Hydra culture growth was partially affected by the variation in ionic

10 compositions (Fig. 3). Ninety six-hour $\mathrm{EC}_{50}$ value for $\mathrm{S} 2$ treatment was significantly

11 lower than for the ONS and S3 types of treatments.

12 The population growth of the paramecia was significantly reduced (Fig. 4),

13 when Ca was eliminated from the media (S2 and S3 types).

\section{Discussion}

\section{General observations}

18 There were no significant differences in toxicity between ON, ONS and S1 (no

19 sulphates and alkalinity) treatments in any of the experiments. While it was expected

20 with $\mathrm{ON}$ and ONS, it also indicated that removal of $\mathrm{SO}_{4}{ }^{2-}$ and Alk did not change the

21 toxicity of salinity in any detectable way. The proportion of these anions is around

$2213 \%$ of the total anions load in ONS, the rest being mostly $\mathrm{Cl}^{-}$. When $\mathrm{S} 1$ and S2

23 treatments were prepared these anions were replaced with $\mathrm{Cl}^{-}$, thus increasing its load.

24 Kefford et al. (2004a) observed that ON was less toxic to freshwater invertebrates 25 than pure $\mathrm{NaCl}$. The lack of a difference in toxicity between ON, ONS and S1 may 
1 indicate that the difference in toxicity between $\mathrm{ON}$ and $\mathrm{NaCl}$ is not because of $\mathrm{Cl}^{-}$

2 toxicity, but rather lack or difficulty in extraction at high salinity of essential and trace

3 elements, such as calcium, potassium, copper, selenium etc. 24- and 48-h $\mathrm{EC}_{50}$ for

4 hydra's tentacle retraction in S1 were slightly higher than in other treatments. We did

5 not specifically test toxicity of $\mathrm{Cl}^{-}$against $\mathrm{SO}_{4}{ }^{2-}$, but other studies with a range of

6 freshwater invertebrate taxa indicate that $\mathrm{Na}_{2} \mathrm{SO}_{4}$ is more toxic than $\mathrm{NaCl}$ (Goetsch

7 and Palmer 1987; Kefford et al. 2004a; Palmer et al. 2004) and that $\mathrm{NaCl}$ is more

8 toxic than $\mathrm{ON}$ (Kefford et al. 2004a). It would therefore appear that $\mathrm{SO}_{4}{ }^{2-}$ is more

9 toxic than $\mathrm{Cl}^{-}$. The replacing of $\mathrm{SO}_{4}{ }^{2-}$ with $\mathrm{Cl}^{-}$could thus have slightly reduced the 10 overall toxicity to hydra.

11 The results regarding treatments with $\mathrm{Ca}$ deficiencies are discussed in detail 12 below.

\section{Acute tests}

15 Short-term acute toxicity testing is usually conducted in sub-optimal conditions for 16 animals tested: static water regime and no food supply. Though these tests convey 17 very useful information on the range of tolerance of the animals to a particular 18 toxicant, which can be very useful in modelling and management on a wider scale, 19 they give very little information on the mechanisms of action or the effects of a 20 toxicant to organisms subject to long exposures and low sub-lethal concentrations.

21 These experiments are therefore usually regarded as a starting point for more detailed 22 long-term sub-lethal exposures, from which one can get more definite information on 23 the effects of a particular toxicant. Though both species were clearly affected by the 24 different ionic compositions in our sub-lethal experiments, it was not so in the acute 25 tests (Table 1). In a short-term exposure with lethal concentrations of salinity, the 
1 different ionic compositions had no detectable effect. Osmoregulatory mechanisms

2 may have played a major part in combating the effects of high salinity, rather than

3 fine-tuned biochemical and physiological interactions. Chapman et al. (2000) found

4 that there were no differences in the survival or swim-up fry toxicity tests (96-h

5 exposure) of rainbow trout embryos in two saline effluents with different ionic

6 proportions. However they found that chironomid larvae grew differently in the

7 different effluent (10-d exposure). The same results were obtained for sulphates-

8 dominated saline lakes in the USA (Dickerson et al. 1996). Though the researchers

9 stated that undiluted lake water was toxic to Ceriodaphnia dubia and attributed this to

10 the differences in ionic composition of major ions, when we recalculated $\mathrm{LC}_{50}(\%$ of

11 dilution) provided by the authors, the $\mathrm{LC}_{50}$ in terms of electrical conductivities were

12 surprisingly similar and not significantly different for C. dubia (except in very saline

13 waters) and fathead minnows. These studies and our results consistently indicate that

14 the short-term lethal toxicity of saline solutions found in nature is not generally

15 affected by different ionic proportion/composition, but longer exposures or sub-lethal

16 effects can reveal the differences. Salinity produced from pure salts (e.g. $\mathrm{NaCl}$,

$17 \mathrm{Na}_{2} \mathrm{SO}_{4}$ ) and one to one ratio of pure salts, neither of which occur in nature, however,

18 do have differing toxicity to that of mixtures of salts (Mount et al. 1997, Kefford et al.

19 2004a, Palmer et al. 2004).

$21 \quad$ Sub-lethal tests

22 There could be several explanations regarding the chronic sub-lethal effects of 23 varying ionic compositions:

24 (1) Direct effect of deficiency of the essential element Ca. 
1 (2) Indirect effect of hardness cations $\left(\mathrm{Ca}^{2+}, \mathrm{Mg}^{2+}\right)$ and carbonates on the biochemistry of the trace-metals.

\section{$4 \quad$ Direct effects of deficiencies in Ca}

\section{$5 \quad$ Effects on paramecia}

6 Paramecia have around 5000 cilia. Movement of the cilia is controlled by their

7 membrane potential. Stimulation of cilia (chemically or physically) activates a

8 voltage-sensitive $\mathrm{Ca}^{2+}$ current associated with the ciliary membrane (Preston and

9 Hammond 1998). This results in avoidance behaviour, making paramecia swim

10 backward (Preston et al. 1992). Nakaoka and Ooi (1985) found that in the presence of

11 ATP as a stimulus in the medium, paramecia swim forward if $\mathrm{Ca}^{2+}$ concentration is

12 below $10^{-6} \mathrm{M}\left(40 \mu \mathrm{g} \mathrm{L}^{-1}\right)$ and backward if it is higher than $10^{-6} \mathrm{M}$. This suggests that,

13 though directional swimming is governed by the intracellular $\mathrm{Ca}^{2+}$ concentration, a

14 minimum amount of calcium in medium is required to maintain normal responses to

15 stimuli. Slightly proportionally higher concentrations of trace metals in S2 and S3

16 (especially at higher salinities) might have affected animals, but lack of calcium in

17 these media did not allow them to respond adequately. In the case of acute toxicity

18 (Table 1) the differences between various ionic composition types were not evident

19 possibly because short-term effect of higher salinity per se was greater than the effect

20 of ionic composition of media, making osmoregulatory mechanism primarily

21 responsible for mortality. At lower salinities in sub-lethal exposures calcium

22 deficiencies might play a greater part in paramecia swimming behaviour, thus making

23 animals in $\mathrm{Ca}^{2+}$-lacking media more prone to abnormal behaviour, and consequently

24 expending more energy. In addition morphogenesis of the complex cell surface

25 during mitosis involves transcellular wave signal, which involves cortical alveoli that 
1 act as Ca reservoir in the cell (Laurent and Fleury 1995). Presumably if there were not enough Ca to initiate the signal, mitosis would be abnormal.

$4 \quad$ Effect on hydra

5 External $\mathrm{Ca}^{2+}$ ions play a major role in the nematocyst discharge in hydrozoans 6 (Salleo et al. 1994a,b, Yanagita 1973, McKay and Anderson 1988; cited in Kawaii et 7 al. 1999). Santoro and Salleo (1991) observed that nematocytes do not discharge in $8 \mathrm{Ca}^{2+}$-free medium, and that $\mathrm{La}^{3+}, \mathrm{Cd}^{2+}$ and $\mathrm{Co}^{2+}$ prevented discharge by blocking the

$9 \mathrm{Ca}^{2+}$ channel even when some $\mathrm{Ca}^{2+}$ is present. Gitter et al. (1994) found that discharge 10 of the stenoteles (a type of nematocyst) in Hydra vulgaris is regulated by a 11 mechanism, allowing intake of $\mathrm{Ca}^{2+}$ from ambient solution. This may explain why 12 hydras were not affected in the acute toxicity test (involving no feeding and therefore 13 no nematocysts discharge) (Table 1), but were growing slower in sub-lethal test 14 (where nematocysts were discharged to capture their prey) in the S2 treatment 15 compared to ONS control (Fig. 3). As there was some $\mathrm{Ca}^{2+}$ present in the M4 16 medium, which was used as control and dilution water for the range of salinities 17 prepared, at higher salinities the effect of blocking $\mathrm{Ca}^{2+}$ by increasing concentrations 18 of $\mathrm{Co}^{2+}$ and $\mathrm{Ni}^{2+}$ (see Auxiliary publication, Table 2) may have begun to play a role. 19 Kawaii et al. (1999) reported that $\mathrm{Mg}^{2+}$ also had an inhibitory effect on atrichous 20 isorhiza (a type of nematocyst) discharge, and that the inhibitory effect of $\mathrm{Mg}^{2+}$ 21 increased when the external concentration of $\mathrm{Ca}^{2+}$ was lowered. This might explain 22 why the S2 type affected sub-lethal salinity tolerance in hydra. S3 type medium, 23 though lacking $\mathrm{Ca}^{2+}$, may not affect hydra as much as an S2 type (Fig. 3) because it 24 also lacked a powerful $\mathrm{Ca}^{2+}$ blocker i.e. $\mathrm{Mg}^{2+}$. 
1 Freshwater hydras reproduce by means of forming buds and developing a foot at

2 the base of a bud and then detaching from the parent. A separated bud was counted as

3 a new animal in our experiments. Zeretzke at al. (2002) found that in Hydra vulgaris

4 (Zurich strain) foot formation was prevented by lowered concentrations of ambient

$5 \mathrm{Ca}^{2+}$, making animals form branches, that persisted on parent's body instead. It would

6 definitely affect the culture growth in our study, as the number of separate individuals

7 has not increased.

\section{$9 \quad$ Increased toxicity of trace metals}

10 Water quality parameters such as hardness and alkalinity can influence the

11 interactions of ions in the ambient solution. Increases in hardness have shown to 12 result in decreased copper toxicity to fish (Pagenkopf 1983) and cladocerans Daphnia 13 magna (Schamphelaere and Janssen 2002) as a result of competition between the 14 hardness metals $(\mathrm{Ca}, \mathrm{Mg})$ and trace-metal species for interaction sites. Welsh et al. 15 (2000) also showed that acute copper toxicity was lower in waters containing 16 proportionately more $\mathrm{Ca}$. They also indicated that $\mathrm{Ca}$ is more important than $\mathrm{Mg}$ in 17 modifying the toxicity of $\mathrm{Cu}$ in rainbow trout and chinook salmon. The same applies 18 to uptake of zinc by rainbow trout (Alsop and Wood 1999) and D. magna (Heijerick 19 et al. 2001), cadmium by D. magna (Penttinen et al. 1998) and the amphipod 20 Hyalella azteca (Jackson et al. 2000), and manganese by brown trout (Stubblefield et 21 al. 1997) in the presence of competing $\mathrm{Ca}^{2+}$ ions. All water types used in our study 22 contained essential and trace metals $\mathrm{Fe}, \mathrm{Mn}, \mathrm{Cu}, \mathrm{Zn}, \mathrm{Mo}, \mathrm{Se}, \mathrm{Li}, \mathrm{Sr}, \mathrm{Br}, \mathrm{Rb}, \mathrm{Co}, \mathrm{V}$, 23 Ni (auxiliary publication, Table 2) that at elevated concentrations can be toxic to 24 aquatic invertebrates. Though the concentration of each trace element was very low, a 25 combined load might be significant in the absence of calcium. Elimination of $\mathrm{Ca}$ 
1 and/or $\mathrm{Mg}$ out of the solution can result, first, in the relative increase of

2 concentrations of trace elements, especially at higher salinities, and second, in

3 increased toxicity of these elements because in the absence of $\mathrm{Ca}$ and/or $\mathrm{Mg}$ more

4 sites are available for binding at the organism-water interface. The hypothesis of

$5 \quad$ increased trace metals toxicity in $\mathrm{Ca}^{2+}$ lacking media remains to be tested.

6 Metal toxicity can also be reduced by complexation with carbonate, thus 7 decreasing the activity of free hydrated metal ions (Barata et al. 1998).

\section{Conclusions}

11 Variation in ionic compositions common in saline inland waters of southeastern 12 Australia did not affect acute lethal salinity tolerance of any species investigated.

13 However the different ionic compositions affected the three sub-lethal responses of 14 investigated species. The water types lacking $\mathrm{Ca}$ had sub-lethally most deleterious 15 effects on the animals. The different responses of invertebrates to various ionic 16 composition types in combination with the sub-lethal range of salinity may be 17 governed by deficiencies of $\mathrm{Ca}$, the chemical interaction of hardness cations, 18 alkalinity and trace metal uptake and toxicity.

19 In assessing the effects of salinity on freshwater invertebrates the ionic 20 proportions should be considered in salinity exposures that are likely to induce sub21 lethal effects.

\section{Acknowledgments}

24 We are grateful for funding from Land and Water Australia (LWA) and the Murray 25 Darling Basin Commission, under the National Rivers Contaminants Program (LWA 
1 Project no. RMI 12), and the Queensland Department of Natural Resources and 2 Mines. We thank Satish Choy, Brendan Edgar, Richard Marchant, Leon Metzeling, 3 Daryl Nielsen, Carolyn Palmer and Phil Papas for their assistance to the project by 4 being members of a steering committee. We also thank Victor Zalizniak for assistance 5 in calculation of ionic proportions of the media. 


\section{References}

2 Agresti, A. (1990). Categorical data analysis. (John Wiley \& Sons, New York, USA)

3 Alsop, D.H., and Wood, C.M. (1999). Influence of waterborne cations on zinc uptake and toxicity in rainbow trout, Oncorhynchus mykiss. Canadian Journal of Fisheries and Aquatic Sciences 56(11), 2112-2119.

Barata, C., Baird, D.J., and Markich, S.J. (1998). Influence of genetic and environmental factors on the tolerance of Daphnia magna Straus to essential and non-essential metals. Aquatic Toxicology 42, 115-137.

Bayly, I. A. E., and Williams, W. D. (1973). 'Inland waters and their ecology.' Camberwell, Longman.

Chapman, P.M., Bailey, H., and Canaria, E. (2000). Toxicity of total dissolved solids associated with two mine effluents to chironomid larvae and early life stages of rainbow trout. Environmental Toxicology and Chemistry 19(1), 210-214.

Dickerson, K.K., Hubert, W.A., and Bergman, H.L. (1996). Toxicity assessment of water from lakes and wetlands receiving irrigation drain water. Environmental Toxicology and Chemistry 15(7), 1097-1101.

Drever, J.J. (1982). 'The Geochemistry of Natural Waters.' $2^{\text {nd }}$ Edn. (Prentice-Hall Inc., New Jersey, USA.)

Elendt, B.-P., and Bias, W.-R. (1990). Trace nutrient deficiency in Daphnia magna cultured in standard medium for toxicity testing. Effects of the optimization of culture conditions on life history parameters of D. magna. Water Research 24(9), 1157-1167.

Gitter, A.H., Oliver, D., and Thurm, U. (1994). Calcium- and voltage-dependence of nematocyst discharge in Hydra vulgaris. Journal of Comparative Physiology A 175, 115-122. 
1 Goetsch, P.A., and Palmer, C.G. (1997). Salinity tolerance of selected macroinvertebrates of the Sabie River, Kruger National Park, South Africa. Archives of Environmental Contamination and Toxicology 32, 32-41.

Heijerick, D.G., De Schamphelaere, K.A.C., and Janssen, C.R. (2002). Predicting acute Zinc toxicity for Daphnia magna as a function of key water chemistry characteristics: development and validation of a biotic ligand model. Environmental Toxicology and Chemistry 21(6), 1309-1315.

Jackson, B.P., Lasier, P.J., Miller, W.P., and Winger, P.W. (2000). Effects of calcium, magnesium, and sodium on alleviating cadmium toxicity to Hyalella azteca. Bullelin of Environmental Contamination and Toxicology 64, 279-286.

Kawaii, S., Yamashita, K., Nakai, M., Takahashi, M., and Fusetani, N. (1999). Calcium dependence of settlement and nematosyst discharge in actinulae of the hydroid Tubularia mesembryanthemum. The Biological Bulletin 196(1), 45-51.

Kefford, B.J., Papas, P.J., and Nugegoda, D. (2003). Relative salinity tolerance of macroinvertebrates from the Barwon River, Victoria, Australia. Marine and Freshwater Research 54, 755-765.

Kefford, B.J., Palmer, C.G., Pakhomova, L., and Nugegoda, D. (2004a). Comparing test systems to measure the salinity tolerance of freshwater invertebrates. Water SA, 30(4), 499-506.

Kefford, B.J., Papas, P.J., Metzeling, L., and Nugegoda, D. (2004b). Do laboratory salinity tolerances of freshwater animals correspond with their field salinity? Environmental Pollution 129, 355-362.

Kefford, B.J., and Nugegoda, D. (2005a). No evidence for a critical salinity threshold for growth and reproduction in the freshwater snail Physa acuta. Environmental Pollution 134, 377-383. 
1 Kefford, B.J., Palmer, C.G., and Nugegoda, D. (2005b). Relative salinity tolerance of freshwater macroinvertebrates from the south-east Eastern Cape, South Africa compared with the Barwon Catchment, Victoria, Australia. Marine and Freshwater Research 56, 163-171.

Kefford, B.J., Palmer, C.G., Jooste, S., Warne, M. St.J., and Nugegoda, D. (in press). What is it meant by ' $95 \%$ of species'? An argument for the inclusion of rapid tolerance testing. Human and Ecological Risk Assessment.

Laurent, M., and Fleury, A. (1995). A model with excitability and relay properties for the generation and the propagation of a $\mathrm{Ca}^{2+}$ morphogenetic wave in Paramecium. Journal of Theoretical Biology 174(2), 227-236.

Lozina-Lozinsky, L.K. (1931). Ernahrungsphysiologie der infusorien. Archiv fur Protistenkunde74, 18-120.

McKay, M.C., and Anderson, P.A.V. (1988). Preparation and properties of cnidocytes from the sea anemone Anthopleura elegantissima. The Biological Bulletin 174, $47-53$.

Marshall, N. A. and P. C. E. Bailey (2004). Impact of secondary salinisation on freshwater ecosystems: effects of contrasting, experimental, short-term releases of saline wastewater on macroinvertebrates in a lowland stream. Marine and Freshwater Research 55(5), 509-523.

Mount, D.R., Gulley, D.D., Hockett, J.R., Garrison, T.D. and Evans, J.M. (1997). Statistical models to predict the toxicity of major ions to Ceriodaphnia dubia, Daphnia magna and Pimephales promelas (flathead minnows). Environmental Toxicology and Chemistry 16, 2009-2019. 
1 Nakaoka, Y., and Ooi, H. (1985). Regulation of ciliary reversal in triton-extracted Paramecium by calcium and cyclic adenosine monophosphate. Journal of Cell Science 77(1), 185-195.

Nielsen, D. L., M. Brock, Crossle, K., Harris, K., Healey, M., and Jarosinski, I. (2003). The effects of salinity on aquatic plant germination and zooplankton hatching from two wetlands sediments. Freshwater Biology 48, 2214-2223.

Pagenkopf, G.K. (1983). Gill surface interaction Model for trace-metal toxicity to fishes: Role of complexation, $\mathrm{pH}$, and water hardness. Environmental Science and Technology 17, 342-347.

Palmer, C.G., Muller, W.J., Gordon, A.K., Scherman, P-A, Davies-Coleman, H., Pakhomova, L. and de Kock, E. (2004). The development of a toxicity database using freshwater macroinvertebrates, and its application to the protection of South African water resources. South African Journal of Science 100, 643-650.

Pinder, A.M., Halse, S.A., McRae, J.M. and Shiel, R.J. (2005). Occurrence of aquatic invertebrates of the wheatbelt region of Western Australia in relation to salinity. Hydrobiologia 543, 1-24.

Pollino, C.A., and Holdway, D.A. (1999). Potential of two hydra species as standard toxicity test animals. Ecotoxicology and Environmental Safety 43, 309-316.

Penttinen, S., Kostamo, A., and Kukkonen, J.V.K. (1998). Combined effects of dissolved organic material and water hardness on toxicity of cadmium to Daphnia magna. Environmental Toxicology and Chemistry 17(12), 2498-2503.

Preston, R.R., Saimi, Y., and Kung., C. (1992). Calcium-dependent inactivation of the calcium current activated upon hyperpolarization of Paramecium tetraurelia. The Journal of General Physiology 100, 253-268. 
1 Preston, R.R., and Hammond, J.A. (1998). Long-term adaptation of $\mathrm{Ca}^{2+}$-dependent behaviour in Paramecium tetraurelia. Journal of Experimental Biology 201, 1835-1846.

Radke, L.C., Howard, K.W.F., and Gell, P.A. (2002). Chemical diversity in southeastern Australian saline lakes I: geochemical causes. Marine and Freshwater Research 53, 941-959.

Radke, L.C., Juggins, S., Halse, S.A., De Deckker, P., and Finston, T. (2003). Chemical diversity in south-eastern Australian saline lakes II: biotic implications. Marine and Freshwater Research 54, 895-912.

Salleo, A., La Spada, G., and Barbera, R. (1994a). Gadolinium is a powerful blocker of the activation of nematocytes of Pelagia noctiluca. Journal of Experimental Biology 187, 201-206.

Salleo, A., La Spada, G., Drago, M., and Curcio, G. (1994b). Hyposmotic shockinduced discharge in acontia of Caliactis parasitica is blocked by gadolinium. Experientia 50, 148-152.

Santoro, G., and Salleo, A. (1991). The discharge of in situ nematocysts of the acontia of Aiptasia mutabilis is a $\mathrm{Ca}^{2+}$ - induced response. Journal of Experimental Biology 156, 173-185.

Sazonova, V.E., Zaliznyak, L.A., Savel'eva, L.M., Morozova, E.V., and Kostyuk, O.B. (1997). Use of bioassays to develop monitoring of water ecosystem. Russian Journal of Ecology 28(3), 207-212.

Schamphelaere, K.A.C. de, and Janssen, C.R. (2002). A biotic ligand model predicting acute copper toxicity for Daphnia magna: The effects of calcium, magnesium, Sodium, Potassium, and pH. Environmental Science and Technology 36, 48-54. 
1 Stubblefield, W.A., Brinkman, S.F., Davies, P.H., Garrison, T.D., Hockett, J.R., and McIntyre, M.W. (1997). Effects of water hardness on the toxicity of manganese to developing brown trout (Salmo trutta). Environmental Toxicology and Chemistry 16(10), 2082-2089.

5 Williams, W.D. (1987). Salinization of rivers and streams: an important 6 environmental hazard. AMBIO 16(4), 180-185.

7 Welsh, P.G., Lipton, J., Chapman, G.A., and Podrabsky, T.L. (2000). Relative 8 importance of calcium and magnesium in hardness-based modification of copper toxicity. Environmental Toxicology and Chemistry 19(6), 1624-1631.

10 Yanagita, T.M. (1973). The 'cnidoblast' as an excitable system. Publications of Seto $11 \quad$ Marine Biological Laboratory 20, 675-693.

12 Zalizniak, L., Kefford, B.J., and Nugegoda, D. (in prep). Is all salinity the same? II. 13 Effects of different ionic compositions on survival and growth of Physa acuta.

14 Zeretzke, S., Perez, F., Velden, K., and Berking, S. (2002). $\mathrm{Ca}^{2+}$-ions and pattern 15 control in Hydra. International Journal of Developmental Biology 46(5), 705-71 
1 Table 1. The $\mathrm{LC}_{50}$ values for animal species tested in acute 96-h experiments.

\begin{tabular}{|c|c|c|c|c|c|}
\hline \multirow[t]{2}{*}{ Species } & \multirow[t]{2}{*}{ Type of treatment } & \multicolumn{4}{|c|}{$\mathrm{LC}_{50}$ values (95\% confidence intervals) } \\
\hline & & $24-\mathrm{h}$ & $48-\mathrm{h}$ & 72-h & $96-\mathrm{h}$ \\
\hline \multirow[t]{5}{*}{ P. caudatum } & $\mathrm{ON}$ & $8.70(7.81-9.67)$ & $8.70(7.81-9.67)$ & NM & $8.70(7.81-9.67)$ \\
\hline & ONS & $8.66(7.77-9.62)$ & $8.66(7.77-9.62)$ & $\mathrm{NM}$ & $8.66(7.77-9.62)$ \\
\hline & S1 & $9.10(8.17-10.17)$ & $8.85(7.93-9.88)$ & NM & $8.85(7.93-9.88)$ \\
\hline & $\mathrm{S} 2$ & $7.24(6.24-7.82)$ & $7.24(6.24-7.82)$ & $\mathrm{NM}$ & $7.24(6.24-7.82)$ \\
\hline & S3 & $7.58(6.65-8.40)$ & $7.38(6.47-8.15)$ & NM & $7.38(6.47-8.15)$ \\
\hline \multirow[t]{5}{*}{ H. oligactis } & ON & $8.95(8.50-9.48)$ & $8.75(8.33-9.32)$ & $8.56(8.15-9.22)$ & $8.37(7.91-9.21)$ \\
\hline & ONS & 9.08 (8.60-9.57) & 8.79 (8.37-9.30) & $8.61(8.20-9.15)$ & $8.35(7.90-8.96)$ \\
\hline & S1 & $9.09(8.63-9.57)$ & $9.09(8.63-9.57)$ & $8.90(8.47-9.40)$ & $8.81(8.39-9.32)$ \\
\hline & $\mathrm{S} 2$ & $9.12(8.66-9.58)$ & $8.86(8.43-9.32)$ & $8.86(8.43-9.32)$ & $8.53(8.07-9.00)$ \\
\hline & $\mathrm{S} 3$ & $9.10(8.63-9.57)$ & $9.10(8.63-9.57)$ & $8.92(8.49-9.39)$ & $8.33(7.76-8.84)$ \\
\hline \multirow[t]{5}{*}{ N. fulva } & ON & $\mathrm{NC}$ & 40.55 & $22.96(20.32-25.56)$ & $18.46(16.10-20.94)$ \\
\hline & ONS & $\mathrm{NC}$ & $33.03(28.91-119.74)$ & $28.17(24.32-37.90)$ & $19.58(7.93-23.90)$ \\
\hline & S1 & $\mathrm{NC}$ & 32.83 & $22.55(19.85-25.55)$ & $18.64(15.89-21.14)$ \\
\hline & $\mathrm{S} 2$ & 60.18 & $29.51(26.74-38.27)$ & 24.20 & $17.97(14.18-21.54)$ \\
\hline & S3 & 97.46 & $23.66(21.28-26.91)$ & $18.27(15.64-21.04)$ & $15.69(13.21-17.92)$ \\
\hline \multirow[t]{5}{*}{ M. robusta } & $\mathrm{ON}$ & 21.44 & 19.08 & $14.51(-8.27-24.92)$ & $13.44(-99.73-32.06)$ \\
\hline & ONS & $25.15(23.17-27.54)$ & 21.45 & 18.70 & 10.51 \\
\hline & S1 & $29.71(25.42-45.73)$ & 23.67 & 17.90 & $15.78(2.96-26.14)$ \\
\hline & $\mathrm{S} 2$ & $27.61(25.57-29.67)$ & 23.76 & 18.02 & 16.46 \\
\hline & S3 & $24.15(15.81-83.88)$ & 19.01 & 14.11 & $11.22(6.65-14.60)$ \\
\hline \multirow[t]{5}{*}{ Centroptilum sp. } & ON & $14.94(12.58-16.97)$ & 9.25 & 6.60 & 5.58 \\
\hline & ONS & 13.61 & $6.33(2.70-9.26)$ & $2.46(-3.49-5.33)$ & $1.75(-3.58-4.21)$ \\
\hline & $\mathrm{S} 1$ & $14.37(12.42-16.76)$ & 10.24 & 6.57 & 4.63 \\
\hline & S2 & $11.32(8.91-13.49)$ & 7.89 & 5.17 & 3.79 \\
\hline & S3 & $10.19(7.75-12.53)$ & $6.38(3.71-8.94)$ & $4.11(0.07-6.89)$ & $3.57(-0.95-6.36)$ \\
\hline
\end{tabular}

$3 \mathrm{NM}$ - not measured, $\mathrm{NC}$ - not calculated (100\% survival in all concentrations). For some values CI could not be calculated. 
a)

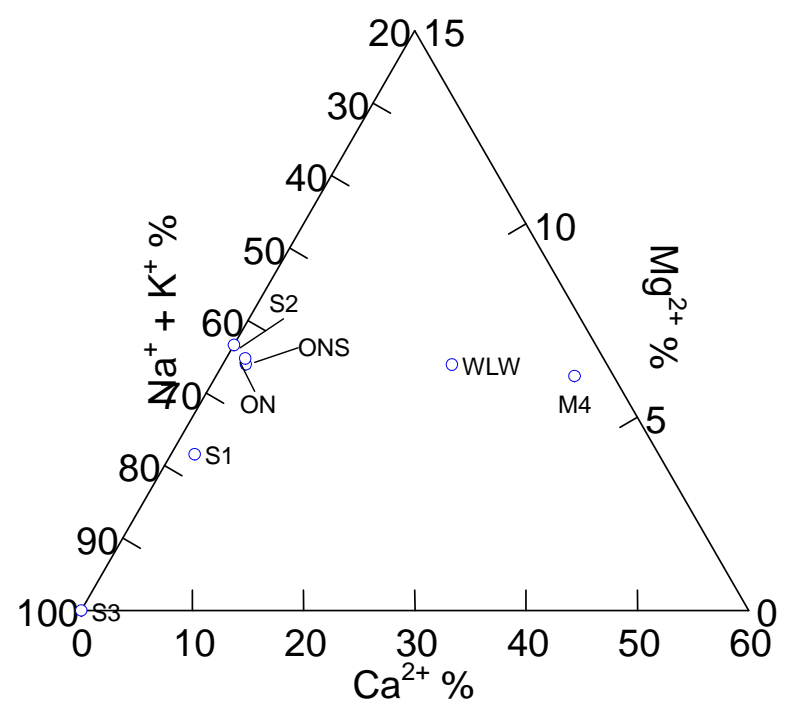

2

3 b)

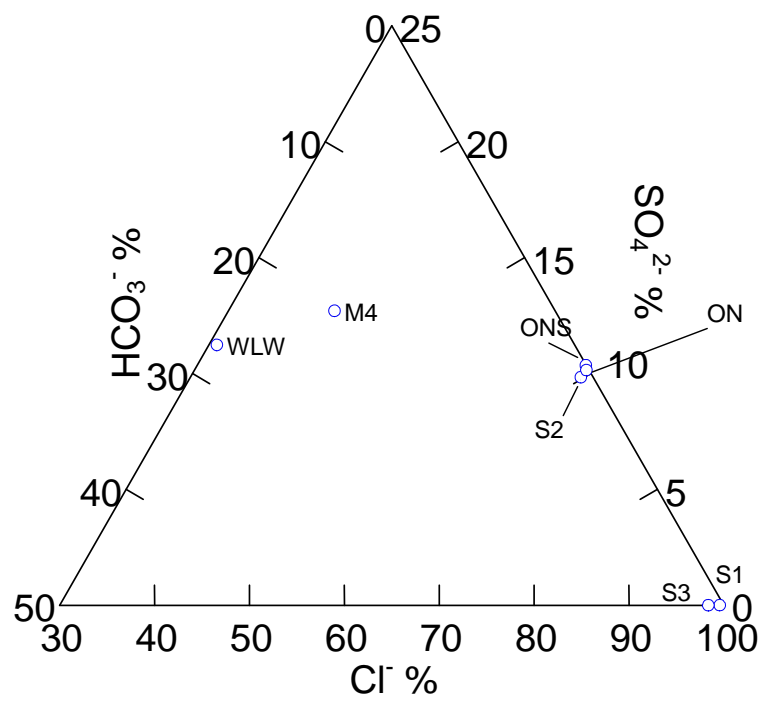

4

5 Fig. 1. Measured ionic proportions of the various saline water types, media (M4) and

6 WLW (see auxiliary publication Table 3 for raw data): a) cations and b) anions as a

7 percentage of the total major cations/anions on a mass to volume basis. 


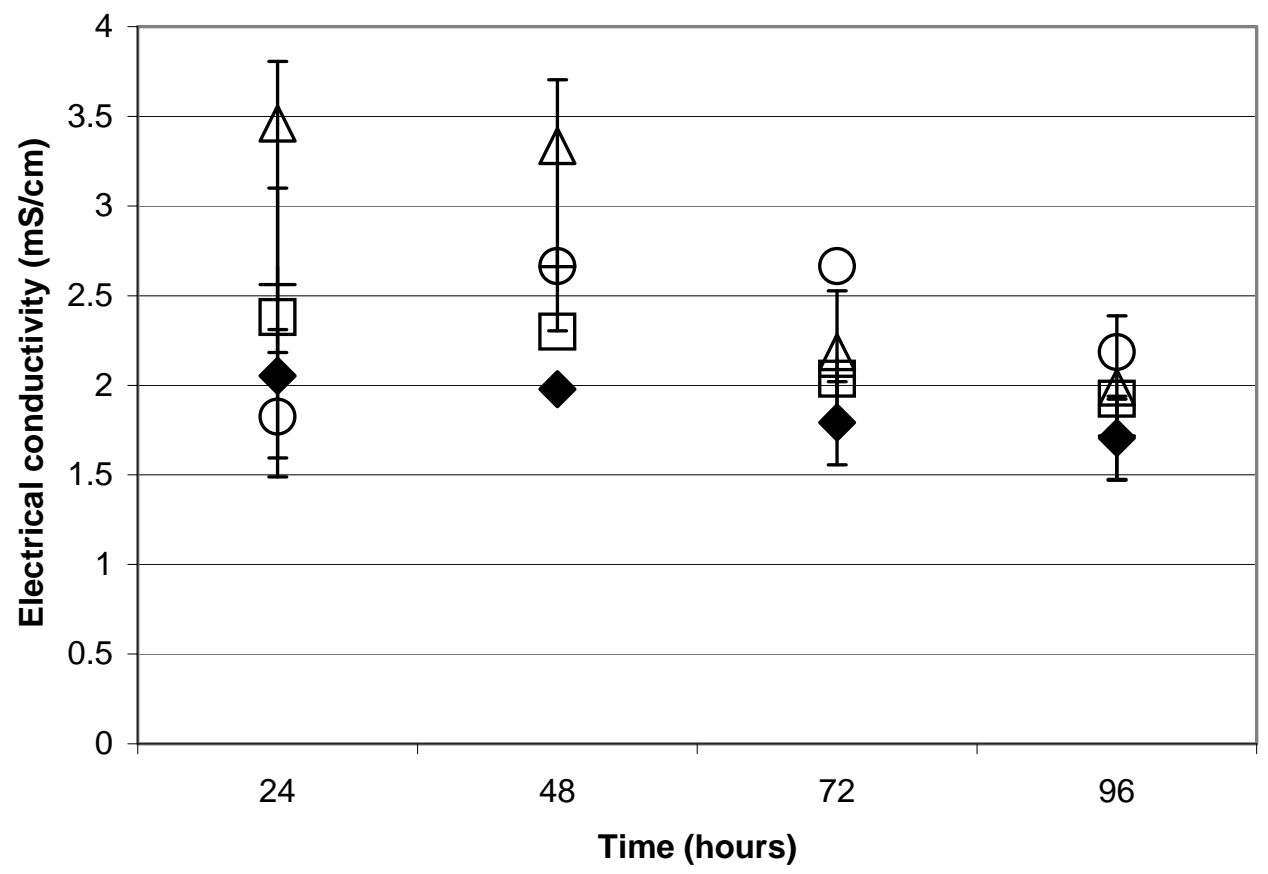

$\bullet$ ON DONS $\triangle \mathrm{S} 1+\mathrm{S} 2$ OS3

2 Fig. 2. Values of $\mathrm{EC}_{50}$ (tentacle retraction) for $H$. oligactis in different types of 3 treatment (error bars indicate $95 \% \mathrm{CI}$ ). 


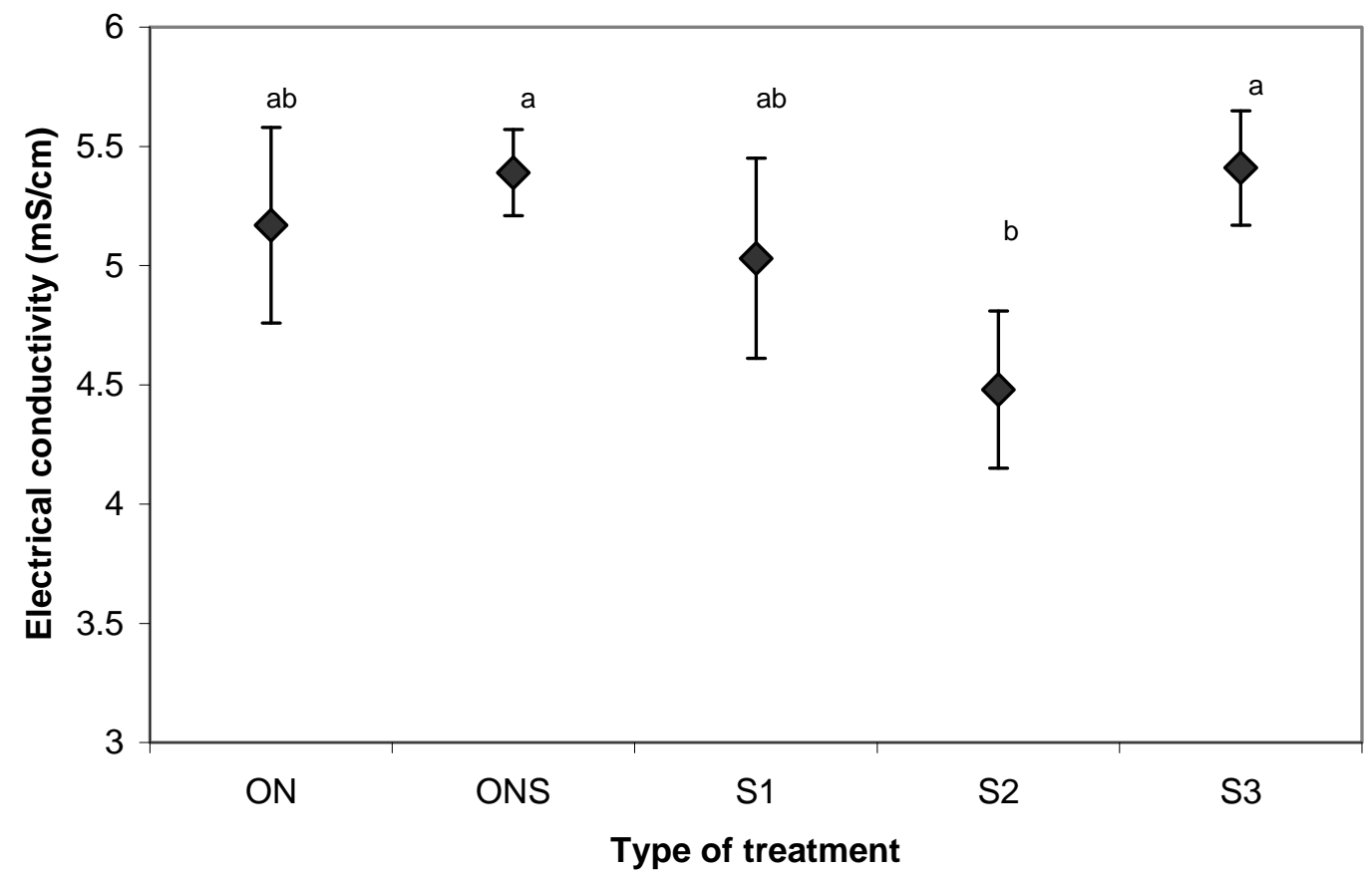

1 Fig. 3. Ninety six-hour $\mathrm{EC}_{50}$ values (culture growth) for $H$. oligactis in different types

2 of treatment (Mean \pm SE, $N=4)$. Different letters represent significantly different

3 results. 


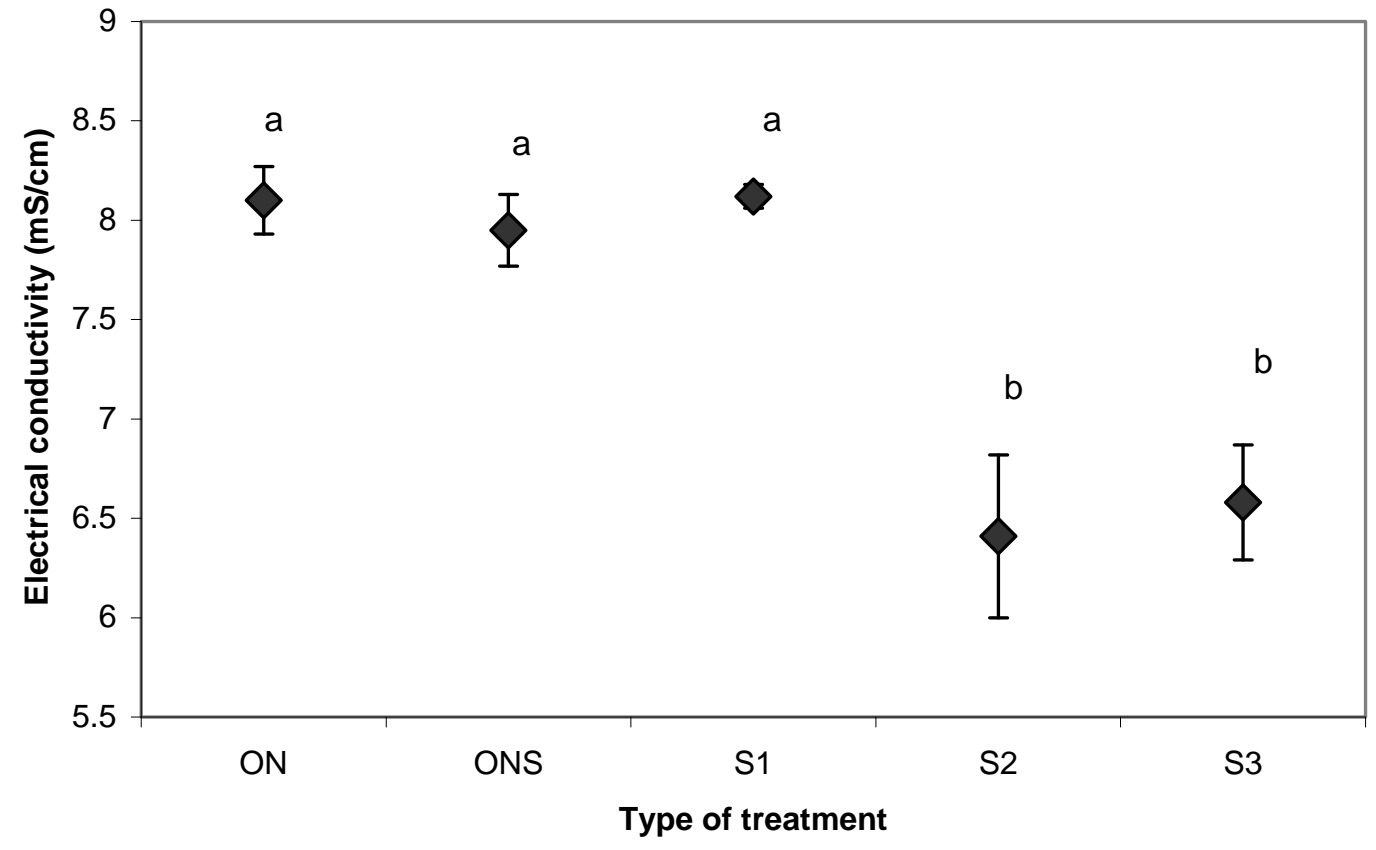

1 Fig.4. Ninety six-hour $\mathrm{EC}_{50}$ values (culture growth) for P. caudatum in different types

2 of treatment (Mean $\pm \mathrm{SE}, \mathrm{N}=10$ ). Different letters represent significantly different 3 results. 